\title{
Experimental infection of BHK21 and Vero cell lines with different Mycoplasma spp.
}

\author{
Cristiane Netto ${ }^{1,3}$, Vanete Thomaz Soccol ${ }^{2}$, Lya Madureira Sepulveda ${ }^{3}$, \\ Jorge Timenetsky ${ }^{4}$ \\ ${ }^{1}$ Mestrado em Biotecnologia Industrial, Universidade Positivo, Curitiba, PR, Brazil. \\ ${ }^{2}$ Programa de Pós Graduação em Engenharia de Bioprocessos e Biotecnologia, \\ Universidade Federal de Curitiba, Curitiba, PR, Brazil. \\ ${ }^{3}$ Ourofino Saúde Animal, Ribeirão Preto, SP, Brazil. \\ ${ }^{4}$ Departamento de Microbiologia, Instituto de Ciências Biomédicas, Universidade de São Paulo, \\ São Paulo, SP, Brazil.
}

Submitted: September 13, 2013; Approved: April 17, 2014.

\begin{abstract}
Mycoplasma spp, belongs to the class Mollicutes and is capable to produce alterations in cellular cultures causing damages to the biotechnological industry. Bioproducts generally require two essential inputs, bovine serum and cells. The study herein aims to evaluate the mycoplasma concentrations that affect the growing of BHK21 and Vero cells. The species used were: Mycoplasma orale, M. salivarium, M. arginini and M. hyorhinis, cultivated in a SP4 media. Two contamination tests were performed with BHK21 and Vero cells and one of them applied different concentrations of mycoplasma. In the first one, mycoplasma was applied at the day zero and, in the second one, the contamination was performed after the monolayer establishment. The both cellular cultures presented cytopathic effects with mycoplasma contamination, but the Vero cells suffered more damages than the BHK21 ones. It was also observed that the severity of the cytopathic effect depended on the mycoplasma specie, on the concentration and on the time of contact with the cellular culture, which evidences the importance of controlling the presence of mycoplasma in biotechnological industries.
\end{abstract}

Key words: growth reduction, PCR, biotechnological products.

\section{Introduction}

Cellular cultures contaminated with mycoplasma represent an artificial habitat for such microorganisms. Studies performed in many countries demonstrated that from 10 to $87 \%$ of the cellular cultures are infected with mycoplasma (Kasemiha et al., 2009; Netto, 2013). The species $M$. orale, $M$. salivarium, $M$. hyorhinis and M. arginini are among the ones that are most found as contaminants (Miyaki et al., 1989; Hu et al., 1995; Timenetsky et al., 2006).

Mycoplasma orale and M. salivarium inhabit the human oropharynx and, generally, they infect cell cultures through inadequate aseptic techniques. $M$. arginini has bovine origin and it is found in cultures from contaminated bovine serum. M. hyorhinis has porcine origin and it can contaminate bovine serum in slaughterhouses when they are also used to slaughter swine (Rottem and Barile, 1993; Smith and Mowles, 1996; Razin et al., 1998).

The contamination through mycoplasma in bovine cells and serum used to produce vaccine antigens or used in diagnosis can generate non-confident results and add potentially noxious effects to biotechnological products. Contaminations through mycoplasma cause alterations in the cellular metabolism, decreasing the cellular division rate through the interference in DNA and RNA synthesis, chromosomal aberrations and death with the monolayer release (Timenetsky et al., 1992). However, there are few studies that quantify which Mycoplasma concentration can affect such growth.

Products, such as vaccines, medicines or monoclonal antibodies, manufactured based on such inputs should be disenabled, which causes prejudices to research laborato- 
ries and to pharmaceutical and biotechnological industries (Uphoff and Drexler, 2002). Thus, the scope of such research was to evaluate the mycoplasma concentrations that affect the growth of BHK21 and Vero cells.

\section{Materials and Methods}

\section{Microorganisms cultivation}

The strains of $M$. orale, $M$. salivarium, $M$. arginini and $M$. hyorhinis were cultivated in $10 \mathrm{~mL}$ of SP4 broth at $37^{\circ} \mathrm{C}$ (Nascimento et al., 2002). The growth of the microorganisms was confirmed due to the acidification of the $\mathrm{pH}$ in the broth, absence of turbidity, production of colonies looking like 'fried eggs' in SP4 agar plates and through polymerase chain reaction (PCR). Mycoplasma was frozen at $-20{ }^{\circ} \mathrm{C}$ with $20 \%$ glycerol (Sigma-Aldrich, St. Louis, MO and USA) up to its usage.

\section{Polymerase chain reaction}

In order to confirm the identity of the mycoplasma strains, a PCR technique standardized by Netto (2013) was used. Briefly, the first step to extract the DNA of the microorganisms, the phenol/chloroform and boiling techniques described by Bashiruddin (1998) were used. The DNA concentration of each sample was measured through the absorbance at $260 \mathrm{~nm}$ (NanoDrop2000, Thermo Scientific, Waltham, MA, USA).

The primer sense GPO-3 5'GGGAGCAAACAGGA TTAGATACCCT3' and the antisense MGSO 5'TGCACCATCTGTCACTCTGTTAACCTC3' were used according to Van Kuppeveld et al. (1994). At the detection through PCR, $2 \mu \mathrm{L}$ of buffer $10 \mathrm{X}, 1.5 \mathrm{mM}$ of $\mathrm{MgCl}_{2}, 0.2 \mu \mathrm{M}$ of each deoxyribonucleotide triphosphate (dNTP), 12.5 pmol of each primer (GPO3/MGSO), $1 \mathrm{U}$ of Taq DNA polymerase (Invitrogen, Carlsbad, CA, USA), $50 \mathrm{ng}$ of DNA (maximum volume of $8 \mu \mathrm{L}$ ) and ultrapure water were added to a final volume of $20 \mu \mathrm{L}$. The thermocycler (model Biocycler MG96) was programmed to one cycle at $94{ }^{\circ} \mathrm{C}$ during $5 \mathrm{~min}, 35$ cycles at $94{ }^{\circ} \mathrm{C}$ during $30 \mathrm{~s}$, $55^{\circ} \mathrm{C}$ during $30 \mathrm{~s}, 72{ }^{\circ} \mathrm{C}$ during $30 \mathrm{~s}$ and a final step at $72{ }^{\circ} \mathrm{C}$ during $5 \mathrm{~min}$.

A negative (ultrapure water) and a positive (DNA of the reference strains) control were added to all amplifications. The expected DNA fragment size after its amplification was of $280 \mathrm{bp}$.

\section{Experimental contamination of BHK21 and Vero cells with Mycoplasma}

Two tests of contamination through mycoplasma in BHK21 and Vero cells were performed. In the test 1, the cellular cultures were contaminated after $24 \mathrm{~h}$ of cultivation and, in the test 2 , the cellular cultures were contaminated from the zero time of cultivation on. The cellular cultures were incubated with microorganisms' serial dilutions (up to $10^{-8}$ ) from the stock. The total time of the cellular cultivation in the both tests was of $48 \mathrm{~h}$ at $37{ }^{\circ} \mathrm{C}$.

$\mathrm{T}$ vials of BHK21 cells in MEM supplemented with $10 \%$ of fetal bovine serum (FBS) and Vero cells in RPMI $1640\left(\right.$ Gibco $^{\circledR}$, Carlsbad, CA, USA) with $10 \%$ of SFB were peaked and incubated at $37{ }^{\circ} \mathrm{C}$ in a stove containing $5 \%$ of $\mathrm{CO}_{2}$ during $48 \mathrm{~h}$. The number of BHK21 cells $/ \mathrm{mL}$ and of Vero cells/mL was counted in a Neubauer chamber. In order to perform the cellular cultivation, a volume of BHK21 or Vero cells corresponding to $0.3 \times 10^{5}$ cells was pipetted and a sufficient quantity of MEM supplemented with $10 \%$ of fetal bovine serum or RPMI media supplemented with $10 \%$ of fetal bovine serum, respectively, were used, totalizing the volume of $150 \mu \mathrm{L} /$ pool.

The both tests were performed in flat-bottomed plates with 96 pools in the same distribution. In the pools from A to $\mathrm{H}$ of the column $1,150 \mu \mathrm{L}$ of MEM supplemented with $10 \%$ of fetal bovine serum or RPMI media supplemented with $10 \%$ of fetal bovine serum were used to prove the sterility of the media used in the test. In the pools from A to $\mathrm{H}$ of the column 2, BHK21 or Vero cells were used as growth controls. In the pools from A to $\mathrm{H}$ of the other columns, serial dilutions from $10^{-1}$ to $10^{-8}$ from stocks cultivated in SP4 broth were pipetted. In the columns 3 and 4, dilutions of $M$. orale were pipetted; in the columns 5 and 6, M. salivarium; in the columns 7 and 8, M. arginini; and, in the columns 9 and 10, M. hyorhinis.

After $48 \mathrm{~h}$ of incubation, the cellular growth was observed and pictured in an inverted microscope with an increase of 100X. Then, the cells were stained with a Crystal Violet solution $0.5 \%$ and the absorbance was checked in a microplate reader at $620 \mathrm{~nm}$ to quantify the cellular growth.

\section{Results}

PCR confirmed the identity of all Mycoplasma strains used in this study and all of them presented the expected product of $280 \mathrm{bp}$ (Figure 1). In the first experiment, the contamination through mycoplasma in BHK21 cells, when compared with the non-contaminated control, showed that, in $M$. orale, the dilutions $10^{-1}$ and $10^{-2}$ presented inferior results of absorbance and, consequently, the percentage of growth reduction was of $15.60 \%$ and of $9.47 \%$, respectively. From the dilution $10^{-3}$ up to the $10^{-8}$, the results were maintained closer to the absorbance values of the negative

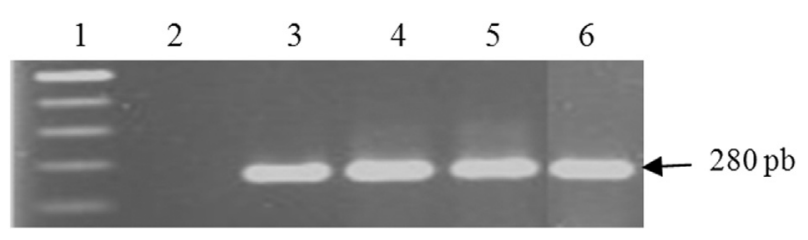

Figure 1 - Agarose gel electrophoresis at 1.5\% of PCR products of mycoplasma grown in SP4 culture media. 1: Molecular Weight Marker (100 pb); 2: Negative Control; 3: M. orale; 4: M. salivarium; 5: $M$. arginini; 6: M. hyorhinis. 
control. For M. salivarium, the dilutions from $10^{-1}$ to $10^{-6}$ presented growth reducing effects from $47.63 \%$ to $13.09 \%$, respectively. The dilutions from $10^{-7}$ to $10^{-8}$ presented results closer to the ones of the negative control. For $M$. arginini, the dilutions $10^{-1}, 10^{-2}$ and $10^{-3}$ presented cytopathic effect with a reduction in the cellular growth of $44.57 \%, 10.31 \%$ and $5.29 \%$, respectively. From the dilutions $10^{-4}$ to $10^{-8}$, the results were maintained closer to the absorbance value of the negative control. For M. hyorhinis, the dilutions from $10^{-1}$ to $10^{-5}$ presented growth reducing effects from $49.86 \%$ to $5.85 \%$, respectively. The dilutions from $10^{-6}$ to $10^{-8}$ presented higher absorbance values (Table 1).

Generally, for BHK cells, in a descending order of cellular growth reduction, the following distribution was observed for the species: $M$. salivarium $>M$. hyorhinis $>M$. arginini $>M$. orale. In the Figure 2, an example of cytophatic effect caused by $M$. salivarium is given.

Experimental contamination with mycoplasma performed in a cultivation of Vero cells, in comparison to the non-contaminated control, showed that, for $M$. orale, the cytopathic effect was higher in the dilutions from $10^{-1}$ to $10^{-3}$ with a growth reduction from $30.70 \%$ to $9.30 \%$, respectively. From the dilution $10^{-4}$ up to the $10^{-8}$, a lower cytopathic effect was observed. For $M$. salivarium, all dilutions presented growth reducing effects from 59.07\% to $7.44 \%$. For $M$. arginini, the dilutions from $10^{-1}$ to $10^{-4}$ presented cytopathic effect with cellular growth reduction from $37.67 \%$ to $5.12 \%$, respectively. For $M$. hyorhinis, the dilutions from $10^{-1}$ to $10^{-5}$ presented growth reducing effects from $39.07 \%$ to $6.05 \%$, respectively (Table 2).

Table 1 - Cytopathic effect in BHK21 cell experimentally infected with different mycoplasma spp. after $24 \mathrm{~h}$ of incubation. The culture was done in MEM medium supplemented with $10 \%$ of Fetal Bovine Serum. The results represent the mean of two replicate and more or less the standard deviation in eight dilutions of mycoplasma. The measure was made by absorbance at $620 \mathrm{~nm}$.

\begin{tabular}{lcccccccc}
\hline & $10^{-1}$ & $10^{-2}$ & $10^{-3}$ & $10^{-4}$ & $10^{-5}$ & $10^{-6}$ & $10^{-7}$ \\
\hline M. orale & $0.303 \pm 0.007$ & $0.325 \pm 0.014$ & $0.352 \pm 0.010$ & $0.355 \pm 0.008$ & $0.358 \pm 0.013$ & $0.359 \pm 0.006$ & $0.361 \pm 0.004$ & $0.366 \pm 0.011$ \\
M. salivarium & $0.188 \pm 0.014$ & $0.269 \pm 0.019$ & $0.277 \pm 0.014$ & $0.279 \pm 0.006$ & $0.29 \pm 0.014$ & $0.312 \pm 0.010$ & $0.343 \pm 0.011$ & $0.353 \pm 0.016$ \\
M. arginini & $0.199 \pm 0.011$ & $0.322 \pm 0.006$ & $0.340 \pm 0.010$ & $0.349 \pm 0.011$ & $0.350 \pm 0.008$ & $0.355 \pm 0.004$ & $0.356 \pm 0.014$ & $0.362 \pm 0.016$ \\
M. hyorhinis & $0.180 \pm 0.016$ & $0.302 \pm 0.016$ & $0.305 \pm 0.015$ & $0.330 \pm 0.011$ & $0.338 \pm 0.011$ & $0.354 \pm 0.011$ & $0.359 \pm 0.018$ & $0.363 \pm 0.016$ \\
\hline
\end{tabular}

Negative control: $0.359 \pm 0.011$
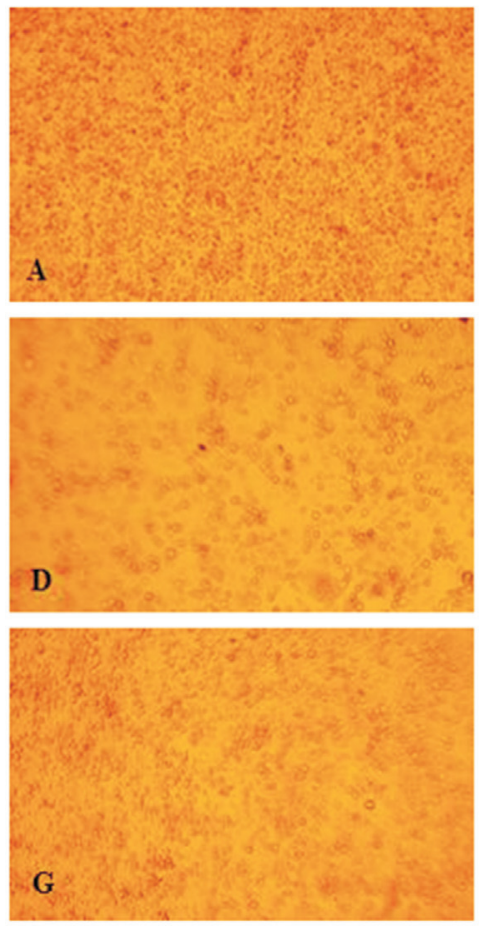
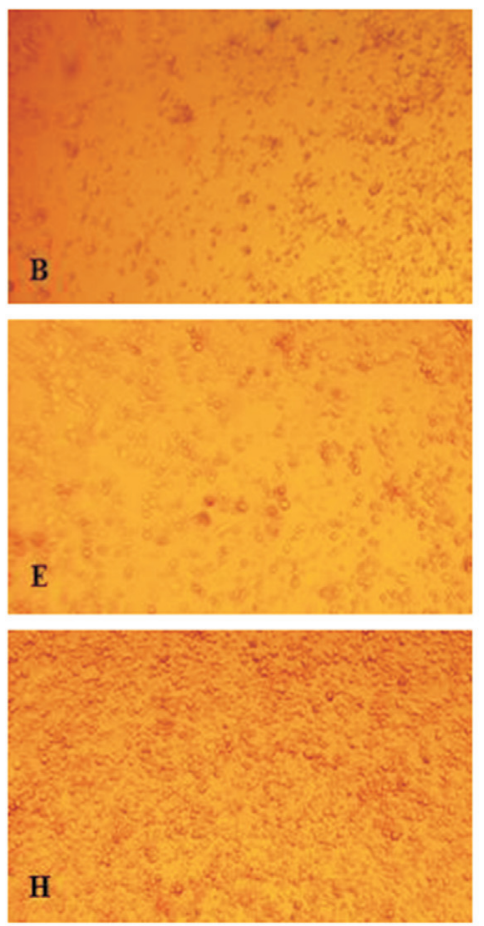
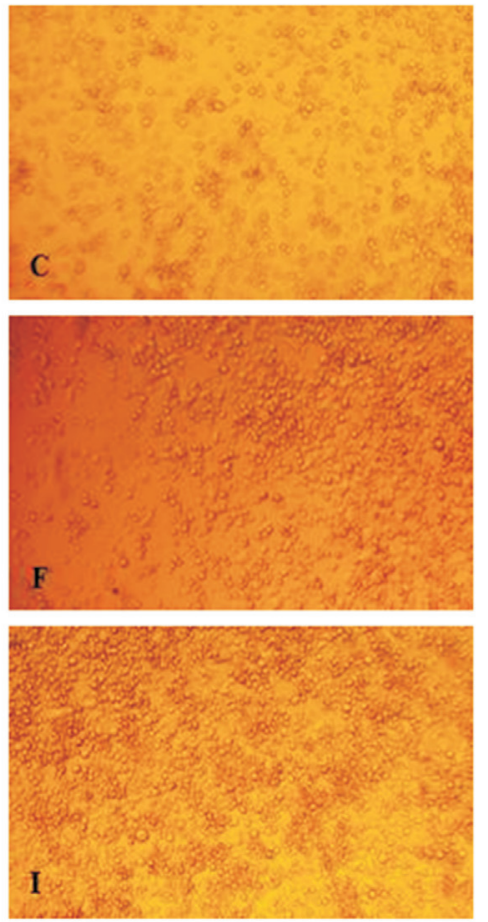

Figure 2 - Culture of BHK21 cells incubated in MEM medium with 10\% of fetal bovine serum (FBS) at $37{ }^{\circ} \mathrm{C}$ by 24 h, after infected experimentally with serial dilutions of Mycoplasma salivarium (X 100). A: Negative Control; the ranges B - I represent BHK21 culture infected by $10^{-1}, 10^{-2}, 10^{-3}, 10^{-4}, 10^{-5}$, $10^{-6}, 10^{-7}$ and $10^{-8}$, respectively. 
Table 2 - Cytopathic effect in Vero cell experimentally infected with different mycoplasma spp. after 24 h of incubation. The culture was done in RPMI 1640 medium supplemented with $10 \%$ of Fetal Bovine Serum. The results represent the mean of two replicate and more or less the standard deviation for eight dilutions of mycoplasma. The measure was made by absorbance at $620 \mathrm{~nm}$.

\begin{tabular}{|c|c|c|c|c|c|c|c|c|}
\hline & $10^{-1}$ & $10^{-2}$ & $10^{-3}$ & $10^{-4}$ & $10^{-5}$ & $10^{-6}$ & $10^{-7}$ & $10^{-8}$ \\
\hline M. orale & $0.149 \pm 0.011$ & $0.163 \pm 0.013$ & $0.195 \pm 0.014$ & $0.210 \pm 0.011$ & $0.212 \pm 0.010$ & $0.215 \pm 0.006$ & $0.217 \pm 0.010$ & $0.217 \pm 0.006$ \\
\hline M. salivarium & $0.088 \pm 0.014$ & $0.089 \pm 0.006$ & $0.104 \pm 0.008$ & $0.111 \pm 0.003$ & $0.157 \pm 0.011$ & $0.187 \pm 0.008$ & $0.194 \pm 0.006$ & $0.199 \pm 0.008$ \\
\hline M. arginini & $0.134 \pm 0.008$ & $0.159 \pm 0.013$ & $0.188 \pm 0.011$ & $0.204 \pm 0.006$ & $0.211 \pm 0.014$ & $0.216 \pm 0.008$ & $0.216 \pm 0.011$ & $0.217 \pm 0.008$ \\
\hline M. hyorhinis & $0.131 \pm 0.011$ & $0.145 \pm 0.018$ & $0.173 \pm 0.017$ & $0.187 \pm 0.011$ & $0.202 \pm 0.014$ & $0.212 \pm 0.011$ & $0.215 \pm 0.014$ & $0.216 \pm 0.011$ \\
\hline
\end{tabular}

Negative control: $0.215 \pm 0.005$.

For Vero cells, in a descending order of effects over the cellular growth reduction, the following distributions are presented: $M$. salivarium $>M$. hyorhinis $>M$. arginini $>$ $M$. orale. In the Figure 3, the cytopathic effect caused by $M$. hyorhinis in Vero cells is shown.

In the evaluation of the infection and of the cytopathic effect of the already established monolayer in BHK21 cells, in comparison to the control that was not contaminated with mycoplasma, it was possible to observe that, for $M$. orale, the dilutions $10^{-1}$ and $10^{-2}$ presented inferior absorbance results and a percentage of growth reduction of $39.40 \%$ and $6.25 \%$, respectively. In the dilutions from $10^{-3}$ up to $10^{-8}$, the results were maintained closer to the absorbance value of the negative control. For M. salivarium, all dilutions presented growth reducing effects from $55.16 \%$ to $13.59 \%$. For $M$. arginini, the dilutions from $10^{-1}$ to $10^{-5}$ presented growth reducing effects from $57.34 \%$ to $4.89 \%$, respec- tively. The dilutions from $10^{-6}$ to $10^{-8}$ presented results closer to the absorbance value of the control. For $M$. hyorhinis, all dilutions presented growth reducing effects from $57.61 \%$ to $15.76 \%$ (Table 3 ). In a descending order of effects over the cellular growth decrease, the following distribution was presented: $M$. hyorhinis $>M$. salivarium $>M$. arginini $>M$. orale. In the Figure 4, an example of cytopathic effect caused by M. salivarium in BHK cell culture is shown.

In the second contamination test performed with Vero cells, in comparison to the control that was not contaminated by mycoplasma, it was checked that the cytopathic effect was observed in all dilutions for all species. The growth reduction varied from $51.38 \%$ to $14.68 \%$ for $M$. orale, from $74.77 \%$ to $43.12 \%$ for $M$. salivarium, from $50.46 \%$ to $29.82 \%$ for $M$. arginini and from $64.68 \%$ to $28.90 \%$ for M. hyorhinis (Table 4). In a descending order of
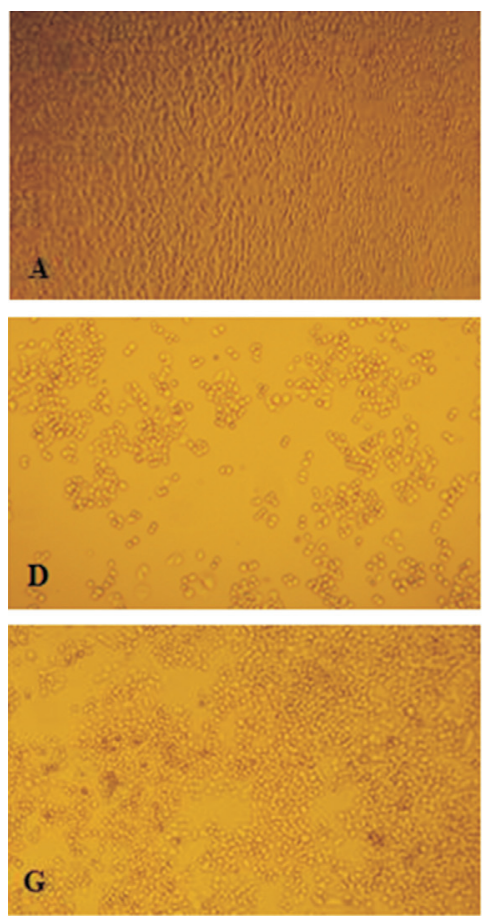
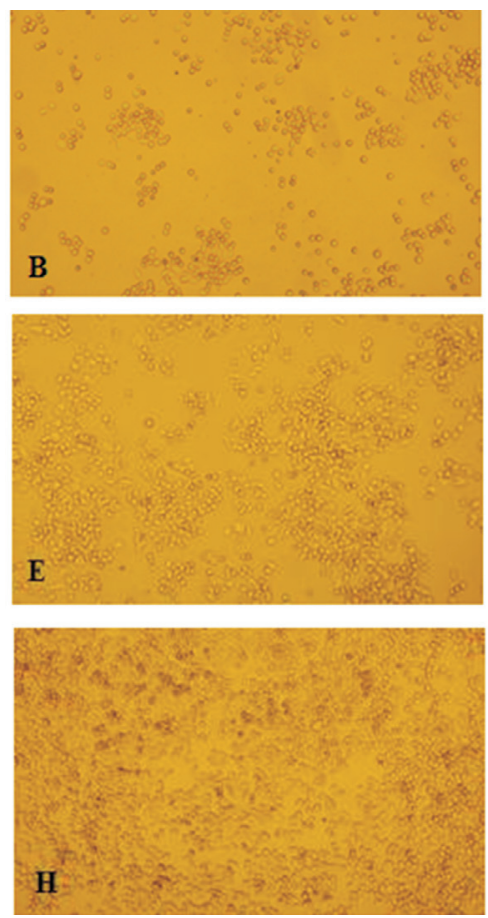
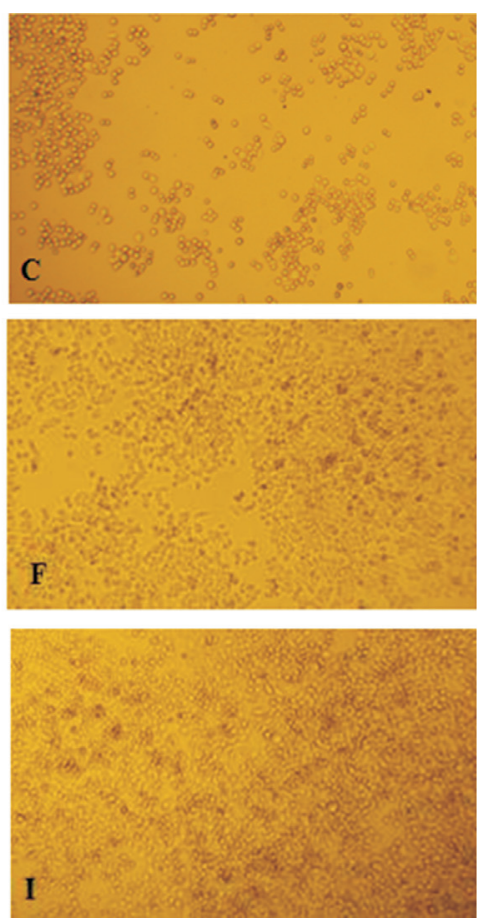

Figure 3 - Culture of Vero cells after $24 \mathrm{~h}$ of cultivation in RPMI 1640 medium supplemented with $10 \%$ of fetal bovine serum (FBS) at $37{ }^{\circ} \mathrm{C}$ and infected experimentally with serial dilutions of Mycoplasma salivarium (X 100). A: Negative Control. The ranges B - I represent Vero cells culture infected by $10^{-1}, 10^{-2}, 10^{-3}, 10^{-4}, 10^{-5}, 10^{-6}, 10^{-7}$ and $10^{-8}$, respectively. 
Table 3 - Cytopathic effect in BHK21 cell experimentally infected with different mycoplasma spp. after 48 h of incubation. The culture was done in MEM medium supplemented with $10 \%$ of Fetal Bovine Serum. The results represent the mean of two replicate and more or less the standard deviation for eight dilutions of mycoplasma. The measure was made by absorbance at $620 \mathrm{~nm}$.

\begin{tabular}{|c|c|c|c|c|c|c|c|c|}
\hline & $10^{-1}$ & $10^{-2}$ & $10^{-3}$ & $10^{-4}$ & $10^{-5}$ & $10^{-6}$ & $10^{-7}$ & $10^{-8}$ \\
\hline M. orale & $0.223 \pm 0.008$ & $0.345 \pm 0.007$ & $0.355 \pm 0.011$ & $0.359 \pm 0.011$ & $0.361 \pm 0.014$ & $0.362 \pm 0.008$ & $0.363 \pm 0.014$ & $0.365 \pm 0.007$ \\
\hline M. salivarium & $0.165 \pm 0.010$ & $0.233 \pm 0.008$ & $0.289 \pm 0.010$ & $0.308 \pm 0.011$ & $0.315 \pm 0.011$ & $0.315 \pm 0.007$ & $0.316 \pm 0.006$ & $0.318 \pm 0.015$ \\
\hline M. arginini & $0.157 \pm 0.014$ & $0.325 \pm 0.006$ & $0.331 \pm 0.009$ & $0.340 \pm 0.011$ & $0.350 \pm 0.007$ & $0.359 \pm 0.011$ & $0.360 \pm 0.011$ & $0.369 \pm 0.008$ \\
\hline M. hyorhinis & $0.156 \pm 0.006$ & $0.257 \pm 0.015$ & $0.268 \pm 0.013$ & $0.278 \pm 0.011$ & $0.280 \pm 0.015$ & $0.283 \pm 0.008$ & $0.289 \pm 0.011$ & $0.310 \pm 0.013$ \\
\hline
\end{tabular}

Negative control: $0.368 \pm 0.013$.
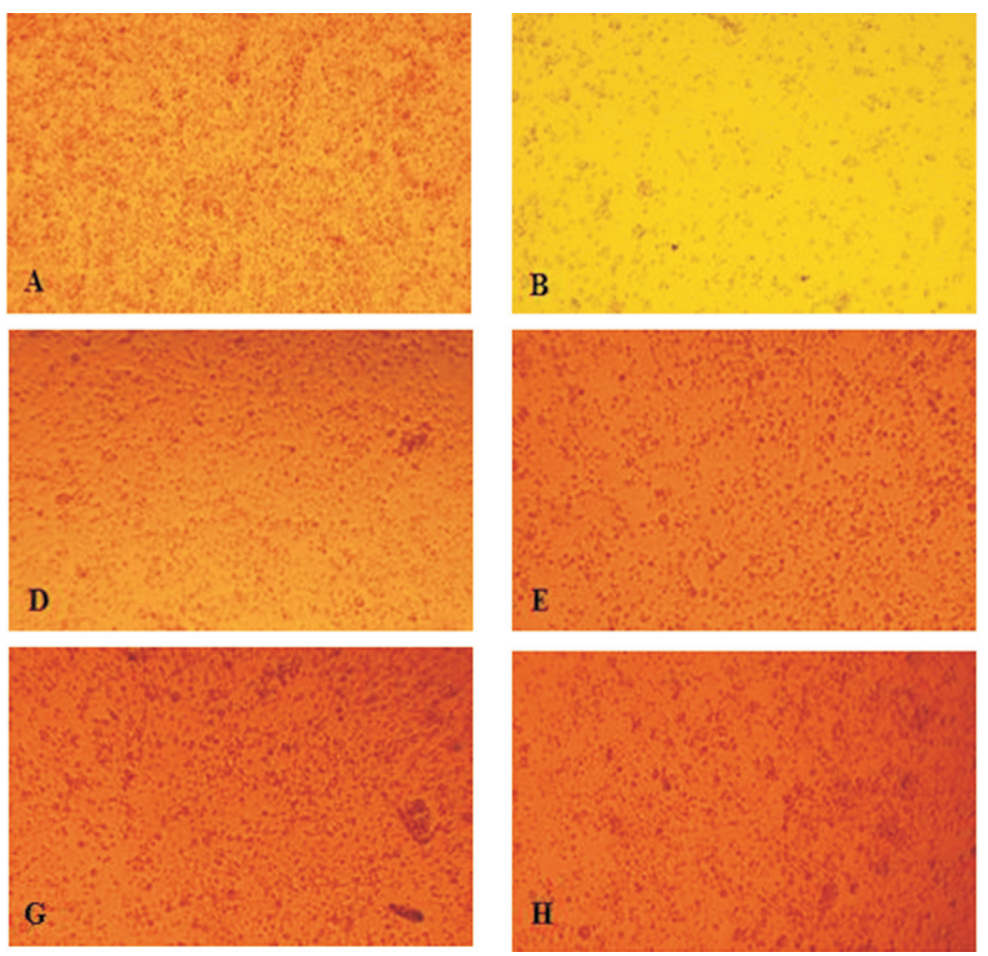
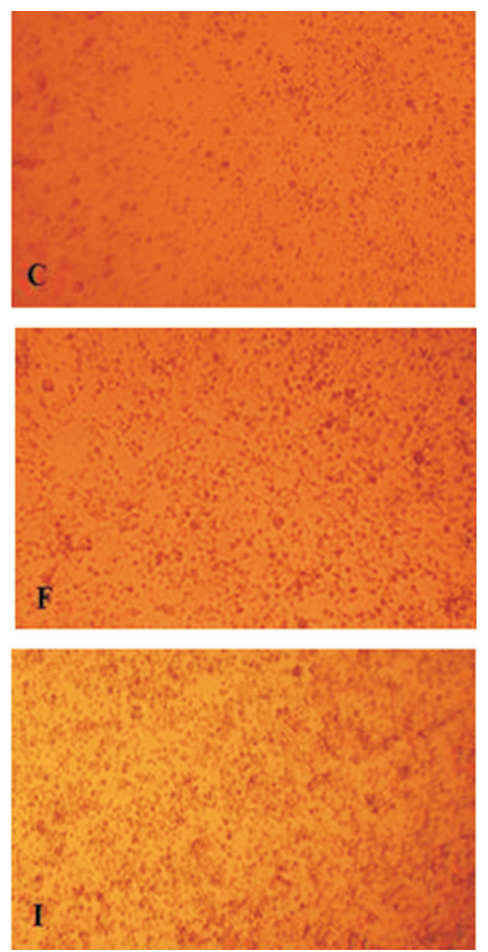

Figure 4 - Cytopathic effect in BHK21 cells after $48 \mathrm{~h}$ cultivation in MEM medium supplemented with $10 \%$ of fetal bovine serum (FBS) at $37{ }^{\circ} \mathrm{C}$ and infected experimentally with serial dilutions of Mycoplasma hyorhinis (X 100). A: Negative control; B - I: $10^{-1}, 10^{-2}, 10^{-3}, 10^{-4}, 10^{-5}, 10^{-6}, 10^{-7}, 10^{-8}$, respectively.

effects over the cellular growth decrease, the distribution of the species is the following: M. salivarium $>M$. hyorhinis $>$ $M$. arginini $>M$. orale. In the Figure 5, the cytopathic effect of $M$. salivarium is shown.

\section{Discussion}

The experimental contamination by mycoplasma in two kinds of cells used to produce immunobiological products showed that, for BHK21 cells, the cytopathic effect was severe for all evaluated species as in the test contaminating the inputs at the beginning of the cultivation as after the monolayer establishment. The contamination after the monolayer produced a higher percentage of cellular growth reduction and/or also a higher number of dilutions that caused such effect. Comparing the results for the BHK21 cells, it was checked, in the test 2 , in which mycoplasma contacted the cellular culture during $24 \mathrm{~h}$ to, then, infect it, that the reduction in the cellular growth was higher. At the test 1 , the specie that caused a more severe effect in the growth of BHK21 cells was M. salivarium. However, in the test 2, M. hyorhinis presented a more severe effect. Thus, it evidences that, in BHK21 cells, M. hyorhinis is capable to cause a higher reduction in the cellular growth with a higher contact time in comparison to other studied species of mycoplasma. In 2003, Rottem reported that M. hyorhinis adhered to each cell and that it was capable to completely destroy the membrane of the host cell, causing a generalized cytopathic effect. 
Table 4 - Cytopathic effect in Vero cell experimentally infected with different Mycoplasma spp. after 48 h of incubation. The culture was done in RPMI 1640 medium supplemented with $10 \%$ of Fetal Bovine Serum. The results represent the mean of two replicate and more or less the standard deviation for eight dilutions of mycoplasma. The measure was made by absorbance at $620 \mathrm{~nm}$.

\begin{tabular}{|c|c|c|c|c|c|c|c|c|}
\hline & $10^{-1}$ & $10^{-2}$ & $10^{-3}$ & $10^{-4}$ & $10^{-5}$ & $10^{-6}$ & $10^{-7}$ & $10^{-8}$ \\
\hline M. orale & $0.106 \pm 0.010$ & $0.120 \pm 0.013$ & $0.152 \pm 0.008$ & $0.154 \pm 0.014$ & $0.154 \pm 0.011$ & $0.159 \pm 0.016$ & $0.173 \pm 0.016$ & $0.186 \pm 0.011$ \\
\hline M. salivarium & $0.055 \pm 0.014$ & $0.065 \pm 0.010$ & $0.089 \pm 0.008$ & $0.092 \pm 0.011$ & $0.110 \pm 0.011$ & $0.121 \pm 0.017$ & $0.122 \pm 0.010$ & $0.124 \pm 0.008$ \\
\hline M. arginini & $0.108 \pm 0.008$ & $0.116 \pm 0.017$ & $0.146 \pm 0.017$ & $0.148 \pm 0.008$ & $0.148 \pm 0.014$ & $0.150 \pm 0.017$ & $0.151 \pm 0.013$ & $0.153 \pm 0.008$ \\
\hline M. hyorhinis & $0.077 \pm 0.014$ & $0.096 \pm 0.008$ & $0.118 \pm 0.011$ & $0.127 \pm 0.011$ & $0.132 \pm 0.014$ & $0.134 \pm 0.014$ & $0.140 \pm 0.017$ & $0.155 \pm 0.014$ \\
\hline
\end{tabular}

Control: $0.218 \pm 0.012$.
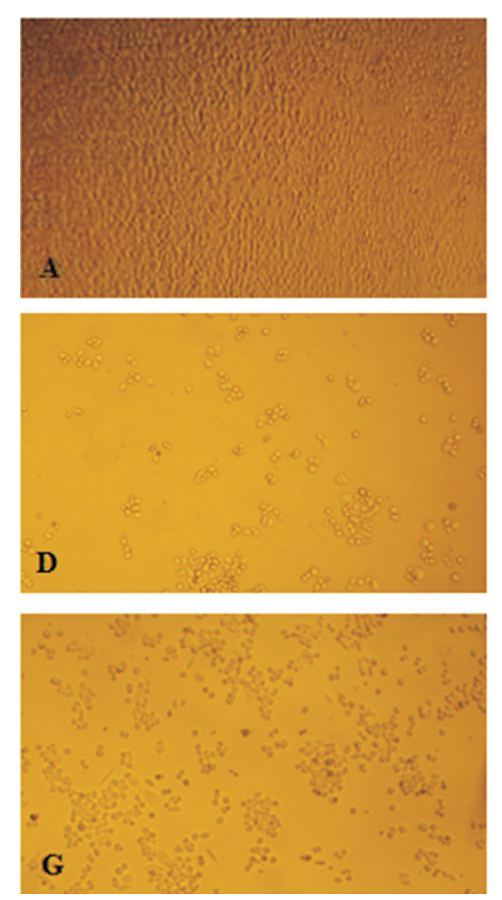
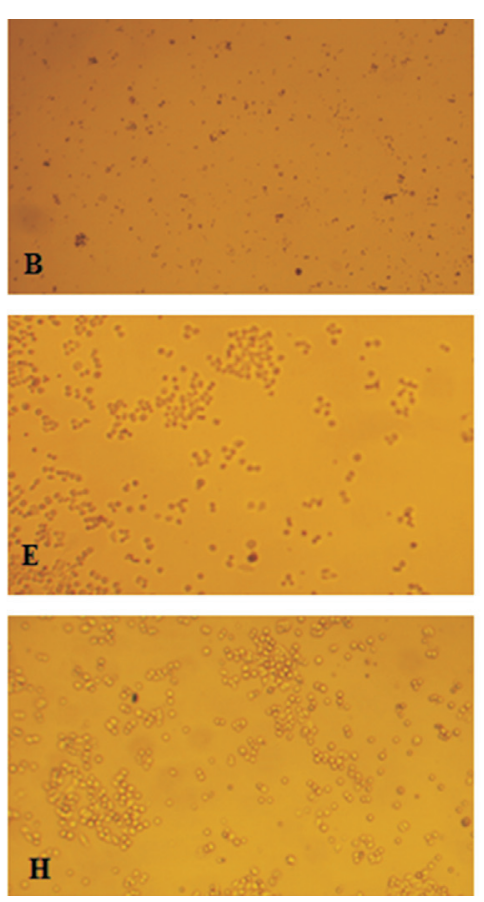
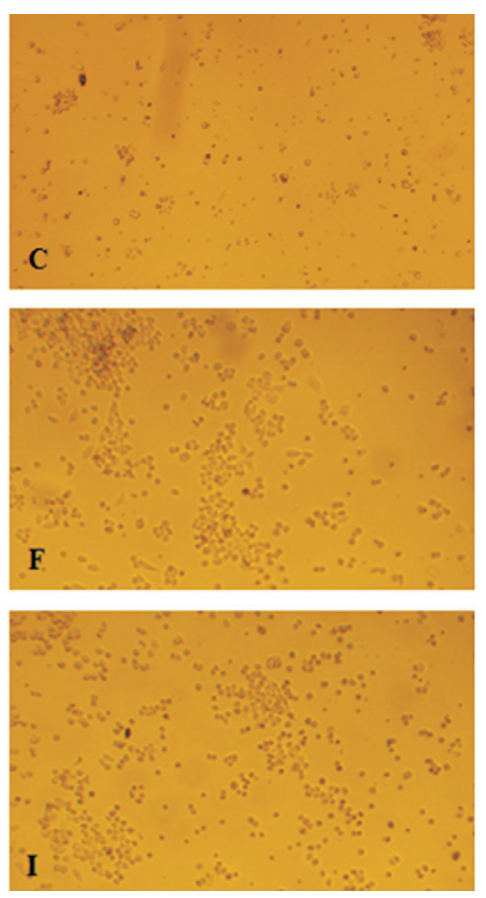

Figure 5 - Vero cells cultures after 48 h of cultivation in RPMI 1640 medium supplemented with $10 \%$ of Fetal Bovine Serum and infected with serial dilutions of Mycoplasma salivarium (X 100). A: Negative Control; B - I: Vero culture with dilution $10^{-1}$ to $10^{-8}$ respectively.

For Vero cells, it was observed that the cytopathic effect was more severe for all species when there was a higher contact with the microorganism. A higher percentage of cellular growth reduction in which the lower concentrations also caused cytopathic effect was checked. For Vero cells, when mycoplasma contacted them during $24 \mathrm{~h}$, a higher reduction in the cellular growth was observed

Through such information, it is possible to evidence that Vero cells had higher cytopathic effects than BHK21 ones in the both tests performed with the same concentrations with all species of mycoplasma. However, the both strains of cellular cultivation had their growth affected in comparison to the control one, especially in the greatest concentrations of the parasite. It was also checked that such effect depends on the mycoplasma specie.

In 2002, Nascimento et al. experimentally contaminated fibrochondrocytes of a rabbit meniscus with many concentrations of mycoplasma during $24 \mathrm{~h}$ and they ob- served that the severity of the cytopathic effect depended on the concentration of the inoculum and on the mycoplasma specie, which are data that corroborate with our research.

Given the harmful effects to cell cultures caused by mycoplasma contamination and, consequently, the financial losses in an attempt to eliminate the contamination or to destruct the infected cell culture, it is essential to emphasize the importance of preventing contamination by these microorganisms. The implementation of quality control of the production process, such as the detection of mycoplasma by PCR from the input to the final product and the use of PPEs, such as masks and gloves, are measured by handlers, which are simpler and cheaper than the damage caused by mycoplasma contamination that is undetected prematurely.

Then, the contamination through mycoplasma causes a reduction in the growth of BHK21 and Vero cells. Vero cells suffered higher cytopathic effects than BHK21 ones in 
the tests and the growth of both of them were affected, especially in higher concentrations of Mycoplasma. It was also observed that the severity of the cytopathic effects depended on the mycoplasma specie, on the concentration and on the duration of the contact with the cellular culture.

\section{Acknowledgments}

Special thanks to the veterinary industry Ourofino Saúde Animal, to its manager Silvia Barioni and its director Dan Artioli, to Dr. Jorge Timenetsky from the University of São Paulo and to Dr. Celso Caricati from Butantan Institute.

\section{References}

Bashiruddin JB (1998) Extraction of DNA from mycoplasmas In: Miles, R. \& Nicholas, R. (eds) Mycoplasma Protocols: A Laboratory Manual. Humana Press, New Jersey.

Domingues D, Nogueira F, Tavira L, Exposto F (2005) Micoplasmas Que papel nas Infecções Humanas? Acta Med Port 18:377-384.

Gopalkrishna V, Verma H, Kumbhar NS, Tomar RS, Patil PR (2007) Detection of Mycoplasma species in cell culture by PCR and RFLP based method: effect of BMcyclin to cure infection. Indian J Med Microbiol 25:364-368.

Hay RJ, Macy ML, Chen TR (1989) Mycoplasma infection of cultured cells. Nature 339:487-488.

Hu M, Buck C, Jacobs D, Paulino G, Khouri H (1995) Application of PCR for detection and identification of Mycoplasma contamination in virus stocks. In vitro cellular and developmental biology. In Vitro Cell Dev Biol Animal 31:710-715.

Kong F, James G, Gordon S, Zelynski A, Gilbert GL (2001) Species specific PCR for identification of common contaminant mollicutes in cell culture. Appl Environ Microbiol 67:3195-3200.

Miyaki C, Pral MM, Gallina NMF, Rizzo E (1989) Micoplasma como contaminante de culturas celulares mantidas em laboratórios de instituições particulares e oficiais. Rev Saúde Públ 23:39-44.

Nascimento CMO, Figueiredo CA, Timenetsky J (2002) Sensitivity of Rabbit Fibrochondrocytes to mycoplasmas. Braz J Microbiol 33:243-246.
Netto C (2013) Detecção de Mycoplasma sp. por PCR para controle de qualidade de imunobiológicos, determinação de concentrações de Mycoplasma sp. que afetam culturas celulares e avaliação da filtração na eliminação destes contaminantes. M.Sc. Dissertation, Mestrado Profissional em Biotecnologia Industrial 99 pp.

Ossewaarde JM, Vries A, Bestebroer T, Angulo AF (1996) Application of a Mycoplasma group-specific PCR for monitoring decontamination of Mycoplasma infected Chlamydia sp. strains. Appl Environ Microbiol 62:328-331.

Razin S, Yogev D, Naot Y (1998) Molecular biology and pathogenicity of mycoplasmas. Microbiol Mol Biol 62:1094-1156.

Rawadi G, Dussurget O (1995) Advances in PCR-based detection of mycoplasmas contaminating cell cultures. Genome Res 4:199-208.

Rottem S, Barile MF (1993) Beware of mycoplasmas. Trends Biotechnol 11:143-151.

Rottem S (2003) Interaction of mycoplasmas with host cells. Physiol Rev 83:413-432.

Smith A, Mowles J (1996) Prevention and control of mycoplasma infection of cell cultures. Molecular and diagnostic procedures in mycoplasmology. Academic Press, San Diego, pp 445-451.

Sung H, Kang SH, Bae YJ, Hong JT, Chung YB, Lee CK, Song S (2006) PCR-based detection of Mycoplasma species. J Microbiol Korea 44:42-49.

Timenetsky J, Miyaki C, Mendes IF, Rizzo E (1992) Identificação de micoplasmas pela inibição de culturas celulares. Rev Saúde Públ 26:17-20.

Timenetsky J, Santos LM, Buzinbani M, Mettifogo E (2006) Detection of multiple Mycoplasma infection in cell cultures by PCR. Braz J Med Biol Res 39:907-914.

Tully JG (1992). Mollicutes. In: Encyclopedia of microbiology. Academic Press, New York, EUA, 181-191.

Uphoff CC, Drexler HG (2002) Comparative PCR analysis for detection of Mycoplasma infections in continuous cells lines. In vitro cellular and developmental biology. In Vitro Cell Dev Biol Animal 38:79-85.

Van Kuppeveld FJM, Johansson KE, Galama JMD, Kissing J, Bölske G, Van Der Logt JTM, Melchers WJG (1994) Detection of mycoplasma contamination in cell cultures by mycoplasma group-specific PCR. Appl Environ Microbiol 60:149-152.

All the content of the journal, except where otherwise noted, is licensed under a Creative Commons License CC BY-NC. 